\title{
Impact of Emergency Medical System Transportation in ST-segment Elevation Myocardial Infarction: A Nationwide Retrospective Study
}

\section{Impacto do Transporte por Viatura Médica de Emergência e Reanimação no Enfarte Agudo do Miocárdio com Elevação do Segmento ST: Estudo Retrospetivo Nacional}

\author{
Júlio Gil PEREIRA $\rrbracket^{1}$, Luís ABREU1, Hugo ANTUNES¹, Maria Luísa GONÇALVES ${ }^{1}$, Bruno MARMELO", \\ Davide MOREIRA ${ }^{1}$, Luís NUNES ${ }^{1}$, Jorge Oliveira SANTOS ${ }^{1}$, on the behalf of the Portuguese National Registry of Acute \\ Coronary Syndromes ${ }^{2}$
}

Acta Med Port 2020 Jun;33(6):390-400 - https://doi.org/10.20344/amp.11082

\section{ABSTRACT}

Introduction: Emergency medical system transportation has been shown to reduce treatment times in ST-segment elevation myocardial infarction. The authors studied the Portuguese National Registry of Acute Coronary Syndromes to determine the nationwide impact of the emergency medical system transportation in the treatment of ST-segment elevation myocardial infarction.

Material and Methods: A multicentric, nationwide, retrospective study of ST-segment elevation myocardial infarction patients inserted in the National Registry from 2010 to 2017 was performed. The patients were divided into: Group I, composed of patients transported by emergency medical system, and Group II, patients arriving to the Emergency department by other means.

Results: Of the 5702 patients studied, $25.9 \%$ were transported via emergency medical system. Rates of emergency medical system activation increased by $17 \%$ in the last 7 years. The emergency medical system provided a higher rate of transport to a percutaneous coronary intervention capable centre, of Emergency department bypass, of on-site fibrinolysis, and ensured a 59-minute reduction of the median reperfusion time $(p<0.001)$. There was no difference in in-hospital mortality.

Discussion: In this nationwide cohort, emergency medical system transportation is associated with a reduction in reperfusion times. It provides a higher amount of salvaged myocardium and reduces the incidence of acute heart failure. However, emergency medical system use did not result in lower in-hospital mortality, probably due to confounding factors of higher disease severity and comorbidity. Conclusion: The benefits associated with emergency medical system based transportation of patients with ST-segment elevation myocardial infarction do not translate into lower in-hospital mortality.

Keywords: Myocardial Reperfusion; Percutaneous Coronary Intervention; ST Elevation Myocardial Infarction; Time Factors; Time-toTreatment

\section{RESUMO}

Introdução: O transporte através de sistemas de emergência médica reduz os tempos de tratamento no enfarte agudo do miocárdio com elevação do segmento ST. Os autores estudaram o Registo Nacional de Síndromes Coronários Agudos para avaliar o impacto nacional do transporte através de sistema de emergência médica no tratamento do enfarte agudo do miocárdio com elevação do segmento ST.

Material e Métodos: Foi realizado um estudo retrospetivo, multicêntrico de doentes com enfarte agudo do miocárdio com elevação do segmento ST inseridos no Registo Nacional desde 2010 até 2017. Os doentes foram divididos em Grupo I, representando doentes transportados por viaturas de emergência médica e Grupo II, doentes que chegaram ao Serviço de Urgência por outros meios.

Resultados: Do total de 5702 doentes, $25,6 \%$ foram transportados por viaturas de emergência médica. Registou-se um aumento no uso de viaturas de emergência médica de $17 \%$ nos últimos sete anos. Os sistemas de emergência médica garantiram uma maior taxa de transporte para centros capazes de realizar intervenção coronária percutânea, de bypass do Serviço de Urgência e de fibrinólise no local. O transporte através de viaturas de emergência médica conseguiu uma redução da mediana do atraso para a reperfusão de 59 minutos $(p<0,001)$. Não houve diferença na mortalidade intra-hospitalar.

Discussão: Nesta amostra nacional, é evidente que os sistemas de emergência médica reduziram significativamente os tempos de reperfusão, associando-se a uma menor incidência de insuficiência cardíaca aguda pós-enfarte. No entanto, esse benefício não resultou numa menor mortalidade intra-hospitalar, provavelmente devido ao facto dessa população representar um subgrupo de doentes com doença mais grave e mais comorbilidades.

Conclusão: Os benefícios associados ao uso de sistemas de emergência médica no transporte de doentes com enfarte agudo do miocárdio com elevação do segmento ST não se traduziram numa menor mortalidade intra-hospitalar.

Palavras-chave: Enfarte Agudo do Miocárdio com Elevação do Segmento ST; Factores de Tempo; Intervenção Coronária Percutânea; Reperfusão Miocárdica; Tempo para Tratamento

\section{INTRODUCTION}

Cardiovascular diseases (CVD), particularly ischemic heart disease (IHD), is the most common cause of death

worldwide..$^{1,2}$ In the past four decades, studies have shown a significant reduction in acute and long-term mortality

\footnotetext{
1. Cardiology department. Hospital de São Teotónio. Centro Hospitalar Tondela-Viseu. Viseu. Portugal.

2. National Registry of Acute Coronary Syndromes. Coimbra. Portugal.

$\bowtie$ Autor correspondente: Júlio Gil Pereira. juliogilpereira@gmail.com

Recebido: 17 de julho de 2018 - Aceite: 28 de outubro de 2019 | Copyright @ Ordem dos Médicos 2020
} 
by acute myocardial infarction (AMI), particularly with STsegment elevation myocardial infarction (STEMI). ${ }^{1-4}$ In Portugal, the same trend was also described in several studies. ${ }^{2,3,5,6}$ It is undeniable that the best treatment for STEMI is revascularization as soon as possible, preferably by primary percutaneous coronary intervention (P-PCI). ${ }^{1,7-9}$ Multiple factors have an impact on the mortality in STEMI patients, such as advanced age, Killip-Kimball class and comorbidities; however, treatment delay is one of the most important factors. ${ }^{1,10}$ Transportation by emergency medical system (EMS) vehicles has been proven to have a definite impact in reducing treatment delays and possibly on mortality. 1,10-15

The Portuguese National Institute of Medical Emergency (INEM) currently employs a special emergency and reanimation medical vehicle (VMER). The VMER is a prehospital intervention vehicle comprised of a specialized staff, which includes a physician and nurse. It is designed for rapid transportation directly to the patient with the goal of ensuring pre-hospital stabilization and medical care prior to hospital admission. The VMER plays an important role in achieving a pre-hospital diagnosis of STEMI and in deciding the best course of action to employ in each case.

In Portugal, the National Registry of Acute Coronary Syndromes (RNSCA) was established in 2002, under the auspice of the Portuguese Society of Cardiology. ${ }^{16}$ It is an observational, multicentric, nationwide prospective study in which each hospital centre participates with data from patients admitted due to acute coronary syndrome (ACS). ${ }^{16}$ Quality control is assured by each participating centre.

The primary goal of the current study is to determine the real-world impact of VMER transportation in patients with STEMI in Portugal. The main objectives include evaluating in-hospital prognosis and determining differences in treatment delays. Information from the RNSCA was analysed to determine the actual nationwide effect of EMS transportation. The secondary objectives were: (1) evaluating which patients were more likely to be transported by VMER; (2) characterization of VMER use nationwide and regionally, as well as evolution trends.

\section{MATERIAL AND METHODS Participants}

This is a retrospective study of patients in the RNSCA from October 1, 2010 to March 14, 2017. Of the 16084 patients included in study period, 5702 were selected, based on the diagnosis of admission (only STEMI patients were chosen) and whether information regarding hospital transportation was available. Patients suffering STEMI while in hospital facilities and hospital transfers were excluded. The decision on which patients were transported via VMER was made on an individual basis, through an algorithm followed by the INEM professionals who receive the distress calls. The patients were divided into two groups, according to the means of transportation: those who were transported by vehicles with medical and nursing staff (VMER) (Group 1) and those who arrived at the hospital through other means (Group 2), either self-comers or by ambulance with- out medical or nursing staff (usually firemen). The groups were compared according to clinical, analytical and procedural parameters, collected upon arrival at the hospital. In-hospital complications were determined as well, namely: (1) Re-infarction (recurrence of ischemia-related chest pain with over 20-minutes duration, ECG changes and new elevation of myocardial biomarkers); (2) Heart failure (HF); (3) Mechanical complication (rupture of the left ventricular free wall, interventricular septum or papillary muscle); (4) De novo Atrial fibrillation (AFib); (5) Second degree atrioventricular block Mobitz II or of higher grade; (6) Sustained ventricular tachycardia (VT) (over 30 seconds of duration or with hemodynamic instability); (7) Aborted cardiac arrest (successful resuscitation after cardiac arrest of any cause); (8) Ischemic or haemorrhagic stroke during hospitalization; (9) Major haemorrhaging (intracranial bleeding or other bleeding associated with hemodynamic compromise requiring intervention according to the GUSTO criteria or transfusion need). The RNSCA has been approved by the Ethics Committee of the Portuguese Society of Cardiology and the National Data Protection Commission (number 3140/2010) and is registered in the platform clinicaltrials.gov (NCT 01642329).

\section{Data analysis}

In the statistical analysis, categorical variables were characterized by absolute and relative frequencies and numerical variables by means and standard deviations. Comparative analyses were carried out in relation to demographic variables, treatment timings, therapeutic strategies, specific interventions and general outcome parameters. Comparisons between two groups regarding the categorical variables were conducted using the chi-square test, or Fisher's Exact test. Regarding the continuous variables, $t$ test was used to compare the means whenever possible, otherwise, the Mann-Whitney $U$ test was used to compare the medians. The chi-square test for trend was considered when evaluating the evolution of VMER use over the years. Predictors of VMER use were determined by adjusting a logistic regression model. The following variables were tested as possible predictors: demographic variables, risk factors, cardiovascular and non-cardiovascular comorbidities, chest pain upon admission. Considering the subsample of patients that use VMER, logistic regression models were also adjusted to determine independent predictors of several outcomes: HF, shock, ventricular arrhythmias, cardiac arrest during hospitalization and in-hospital mortality. Variables were selected to be included in the model using the Stepwise (Forward) method, together with the LikelihoodRatio test. For each variable included in the regression model, the adjusted odds ratio and the respective 95\% confidence interval ( $\mathrm{Cl}$ 95\%) were also estimated. Model calibration was assessed by Hosmer and Lemeshow test. The quality of the adjustment of the logistic regression models was assessed by determining the area under the receiver operating characteristic curve (AUC). Statistical analyses were conducted using SPSS $19.0^{\circledR}$, at a $5 \%$ significance 
level for hypothesis-testing.

\section{RESULTS}

\section{Patients' Characteristics}

A total of 5702 patients were studied, of which 1474 (25.9\%) were transported by VMER. Regarding Group $2,33.0 \%$ of patients were transported by an ambulance without a physician and $55.0 \%$ arrived at the Emergency department (ED) through their own means. The general characteristics of each group are displayed in Table 1. Table 2 displays the predictors of EMS transportation. Men $(p=$ 0.005 ), patients with more cardiovascular risk factors and patients with known coronary disease are more frequently transported by EMS. Chest pain characteristics were also predictors of EMS use. Patients who presented with lower blood pressure $(p<0.001)$ or suffered cardiac arrest $(p<$ 0.001 ) were more likely to be transported by EMS. There was a significantly lower value of BNP in patients transported via VMER $(p<0.001)$. VMER registered a higher rate of direct admission to a Cath lab and of ED bypass $(p<0.001)$. VMER also showed a greater likelihood of transport to a $\mathrm{PCl}$-capable centre $(p<0.001)$.

\section{Regional differences and temporal evolution}

VMER use throughout the regions is displayed in Table 1. Northern Portugal has significantly less VMER use. On the contrary, almost $60 \%$ of patients are transported by EMS in the Southern region and the Islands (Madeira and Azores). In Fig. 1, the temporal evolution of each region is shown. While there was no difference in the Northern region $(p=0.078)$, the other regions all showed a significant increase in EMS use $(p<0.001)$. This increase translates into a steady and significant rise in the VMER use nationwide (Fig. 2).

\section{Treatment delays}

Transportation by EMS vehicles had a significant impact on the time it took to treat patients. The overall timings are displayed in Table 3. EMS consistently reduced almost all measurable timings $(p<0.05)$, thus effectively reducing both patient-delay and system-delay. The only two timings in which EMS did not have an impact were timings regarding fibrinolytic therapy (FT). However, the overall time between symptoms and beginning of FT was significantly reduced $(p=0.012)$.

Table $1-$ Characterization of the sample $(n=5702)$ (first section)

\begin{tabular}{|c|c|c|c|}
\hline & $\begin{array}{l}\text { STEMI transported by } \\
\text { emergency vehicles } \\
(n=1474)\end{array}$ & $\begin{array}{l}\text { STEMI transported } \\
\text { through other means } \\
(\mathrm{n}=\mathbf{4 2 2 8})\end{array}$ & $p$ \\
\hline Age, years old (mean \pm SD) & $64 \pm 13$ & $64 \pm 14$ & 0.674 \\
\hline Male gender, n (\%) & 77.5 & 73.8 & 0.005 \\
\hline Body mass index, $\mathrm{kg} / \mathrm{m}^{2}($ mean $\pm \mathrm{SD})$ & $27.3 \pm 4.5$ & $27.0 \pm 4.2$ & 0.034 \\
\hline - Low weight, n (\%) & $15(1.1)$ & $22(0.6)$ & 0.045 \\
\hline - Obesity, n (\%) & $309(23.0)$ & 759 (19.9) & 0.018 \\
\hline \multicolumn{4}{|l|}{ Regions of Portugal } \\
\hline Northern Portugal ${ }^{1}, \mathrm{n}(\%)$ & $79(5.4)$ & $1416(33.5)$ & $<0.001$ \\
\hline Central Portugal ${ }^{2}, \mathrm{n}(\%)$ & $541(36.7)$ & $1487(35.2)$ & 0.189 \\
\hline Southern Portugal and Islands ${ }^{3}, \mathrm{n}(\%)$ & $854(57.9)$ & $1325(31.3)$ & $<0.001$ \\
\hline \multicolumn{4}{|l|}{ Cardiovascular risk factors } \\
\hline Arterial hypertension, $\mathrm{n}(\%)$ & $872(60.9)$ & $2549(61.4)$ & 0.710 \\
\hline Diabetes mellitus, n (\%) & $312(21.8)$ & $1034(25.0)$ & 0.016 \\
\hline Dislypidemia, n (\%) & $769(55.4)$ & $1994(50.4)$ & 0.001 \\
\hline Smoking habits, n (\%) & $568(38.9)$ & $1498(35.5)$ & 0.022 \\
\hline Family history of coronary disease, $\mathrm{n}(\%)$ & $108(8.3)$ & $269(7.6)$ & 0.454 \\
\hline Previous acute myocardial infarction, $\mathrm{n}(\%)$ & $196(13.4)$ & $388(9.2)$ & $<0.001$ \\
\hline Previous percutaneous coronary intervention, $\mathrm{n}(\%)$ & $178(12.2)$ & $311(7.4)$ & $<0.001$ \\
\hline Previous coronary artery bypass graft, n (\%) & $16(1.1)$ & $46(1.1)$ & 0.997 \\
\hline Peripheral artery disease, $\mathrm{n}(\%)$ & $57(3.9)$ & $119(2.8)$ & 0.037 \\
\hline \multicolumn{4}{|l|}{ Comorbidities } \\
\hline Heart failure, $\mathrm{n}(\%)$ & $27(1.8)$ & $92(2.2)$ & 0.433 \\
\hline Chronic obstructive pulmonary disease, $\mathrm{n}(\%)$ & $57(3.9)$ & $159(3.8)$ & 0.853 \\
\hline Dementia, n (\%) & $36(2.5)$ & $83(2.0)$ & 0.206 \\
\hline Previous stroke or transient ischemic attack, $\mathrm{n}(\%)$ & $84(5.7)$ & $273(6.5)$ & 0.313 \\
\hline Chronic kidney disease, n (\%) & $40(2.7)$ & $138(3.3)$ & 0.299 \\
\hline
\end{tabular}


Table 1 - Characterization of the sample $(n=5702)$ (final section)

\begin{tabular}{|c|c|c|c|}
\hline & $\begin{array}{l}\text { STEMI transported by } \\
\text { emergency vehicles } \\
(n=1474)\end{array}$ & $\begin{array}{l}\text { STEMI transported } \\
\text { through other means } \\
(\mathrm{n}=4228)\end{array}$ & $p$ \\
\hline \multicolumn{4}{|l|}{ Clinical data at admission } \\
\hline Anterior acute myocardial infarction, $\mathrm{n}(\%)$ & $719(48.8)$ & $2040(48.2)$ & 0.710 \\
\hline Inferior acute myocardial infarction, n (\%) & $746(50.6)$ & $2142(50.7)$ & 0.991 \\
\hline New left bundle branch block, $\mathrm{n}(\%)$ & $8(0.5)$ & $46(1.1)$ & 0.063 \\
\hline Chest pain, n (\%) & $1381(93.7)$ & $3936(93.1)$ & 0.432 \\
\hline - Pain at rest, $\mathrm{n}(\%)$ & $1270(95.7)$ & $3725(95.8)$ & 0.933 \\
\hline - Pain present at admission, $\mathrm{n}(\%)$ & $1156(87.9)$ & $3328(85.4)$ & 0.021 \\
\hline - Episodic chest pain, $\mathrm{n}(\%)$ & $315(24.3)$ & $1307(34.1)$ & $<0.001$ \\
\hline Cardiac arrest, n (\%) & $26(1.8)$ & $20(0.5)$ & $<0.001$ \\
\hline Heart rate, bpm (mean $\pm \mathrm{SD})$ & $77 \pm 21$ & $78 \pm 20$ & 0.369 \\
\hline Systolic blood pressure, $\mathrm{mmHg}($ mean $\pm \mathrm{SD})$ & $132 \pm 30$ & $135 \pm 30$ & $<0.001$ \\
\hline Diastolic blood pressure, $\mathrm{mmHg}($ mean $\pm \mathrm{SD})$ & $78 \pm 18$ & $80 \pm 18$ & $<0.001$ \\
\hline Killip-Kimball class I, n (\%) & $1254(85.4)$ & $3616(86.0)$ & 0.617 \\
\hline Killip-Kimball class II, n (\%) & $112(7.6)$ & $359(8.5)$ & 0.280 \\
\hline Killip-Kimball class III, n (\%) & $41(2.8)$ & $144(2.1)$ & 0.121 \\
\hline Killip-Kimball class IV, n (\%) & $61(4.2)$ & $144(3.4)$ & 0.195 \\
\hline Killip-Kimball class II + III + IV, n (\%) & $214(14.6)$ & $591(14.0)$ & 0.617 \\
\hline \multicolumn{4}{|l|}{ Laboratory data } \\
\hline Creatinine at admission, mg/dL, median (P25; P75) & $0.9(0.8 ; 1.1)$ & $0.9(0.8 ; 1.1)$ & 0.214 \\
\hline Maximum creatinine, mg/dL, median (P25; P75) & $1.0(0.8 ; 1.3)$ & $1.0(0.9 ; 1.3)$ & 0.26 \\
\hline Glycemia, mg/dL, median (P25; P75) & $141(116 ; 186)$ & $135(111 ; 174)$ & $<0.001$ \\
\hline Hemoglobin at admission, g/dL (mean \pm SD) & $14 \pm 1.8$ & $14 \pm 1.9$ & 0.491 \\
\hline Hemoglobin, minimum value, g/dL (mean \pm SD) & $12.8 \pm 2.0$ & $12.6 \pm 1.9$ & 0.025 \\
\hline Platelets, x 106/L, median (P25; P75) & $213(177 ; 252)$ & $214(179 ; 260)$ & 0.243 \\
\hline BNP, pg/ml, median (P25; P75) & $143(46 ; 363)$ & $195(76 ; 465)$ & $<0.001$ \\
\hline \multicolumn{4}{|l|}{ GRACE score } \\
\hline - Low risk, n (\%) & $47(3.3)$ & $129(3.3)$ & \\
\hline - Intermediate risk, n (\%) & $354(25.0)$ & $1046(26.7)$ & 0.432 \\
\hline - High risk, n (\%) & $1017(71.7)$ & $2739(70.0)$ & \\
\hline \multicolumn{4}{|l|}{ Hospital admission } \\
\hline Emergency department, n (\%) & $354(24.1 \%)$ & $2005(47.6 \%)$ & $<0.001$ \\
\hline Coronary intensive care unit, n (\%) & $396(26.9 \%)$ & $1028(24.4 \%)$ & 0.060 \\
\hline Catheterization lab, n (\%) & $717(48.7 \%)$ & $1169(27.7 \%)$ & $<0.001$ \\
\hline Admission to a non-PCl-capable centre, $\mathrm{n}(\%)$ & $323(22.3 \%)$ & $1725(41.7 \%)$ & $<0.001$ \\
\hline
\end{tabular}

Note: The following Portuguese regions were considered: (1) Northern Portugal, from Oliveira de Azeméis to the north; (2) Central Portugal, from Aveiro and Viseu to Lisbon; (3) Southern Portugal and Islands, from Almada and Barreiro to Faro including Madeira and Azores.

Table 2 - Predictors of EMS transportation

\begin{tabular}{lcccc}
\hline Predictors & Beta & OR & Confidence interval 95\% & $p$ \\
\hline Low Weight & 0.881 & 2.41 & $1.20-4.84$ & 0.013 \\
Obesity & 0.191 & 1.21 & $1.3-1.43$ & 0.024 \\
Female sex & -0.238 & 0.79 & $0.67-0.93$ & 0.005 \\
Previous Angina & 0.321 & 1.38 & $1.14-1.67$ & 0.001 \\
Previous PCl & 0.418 & 1.52 & $1.21-1.90$ & $<.001$ \\
Chest pain present at admission & 0.253 & 1.29 & $1.08-1.54$ & 0.006 \\
Episodic chest pain & 0.083 & 0.59 & $0.50-0.70$ & $<0.001$ \\
\hline
\end{tabular}

Hosmer-Lemeshow test $p$ - value of 0,$365 ; \mathrm{AUC}(\mathrm{Cl} 95 \%)$ of $0.588(0.570 ; 0.606)$ 


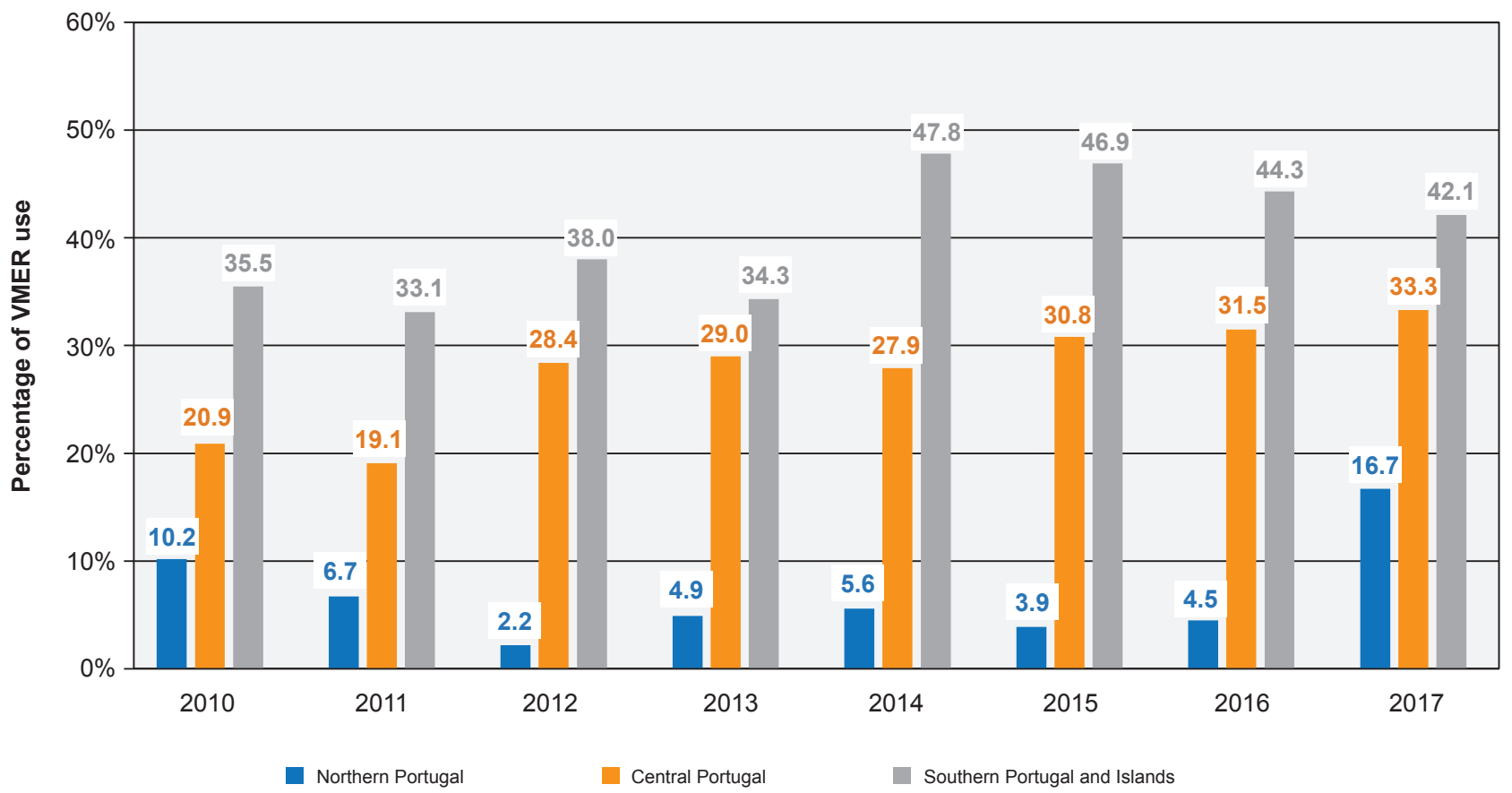

Figure 1 - Evolution of VMER use throughout the years in the different regions

Chi-square test for Trend: Northern region $p=0.078$; Central region $p<0.001$ and Southern region and Islands $p<0.001$

\section{Therapeutic strategies and other interventions}

The multiple therapeutic strategies, results from coronary angiography and other interventions are displayed in Table 4. There is a significantly higher use of FT $(p=0.042)$, particularly pre-hospital fibrinolysis in the VMER group $(p<$ 0.001 ), in probable relation to expectable delay in the transfer to a PCl-capable centre. There was a higher rate of total occlusions of left main coronary artery $(p=0.003)$, the left anterior descending artery $(p=0.017)$ and the right coronary artery $(p=0.001)$ in the EMS group. There is more application of intra-aortic balloon pump $(p=0.012)$ and of non- invasive mechanical ventilation $(p=0.006)$ in Group 2. On the other hand, Group 1 needed significantly more invasive mechanical ventilation $(p<0.001)$. There are significantly higher values of left ventricular ejection fraction (LVEF) in patients transported by VMER $(p<0.001)$.

\section{In-hospital mortality and complications}

The rate of complications and in-hospital mortality are displayed in Table 5. Regarding in-hospital complications, there is a higher rate of sustained VT $(p=0.005)$ and aborted cardiac arrest $(p<0.001)$ in Group 1. On the other

\section{Percentage of VMER use}

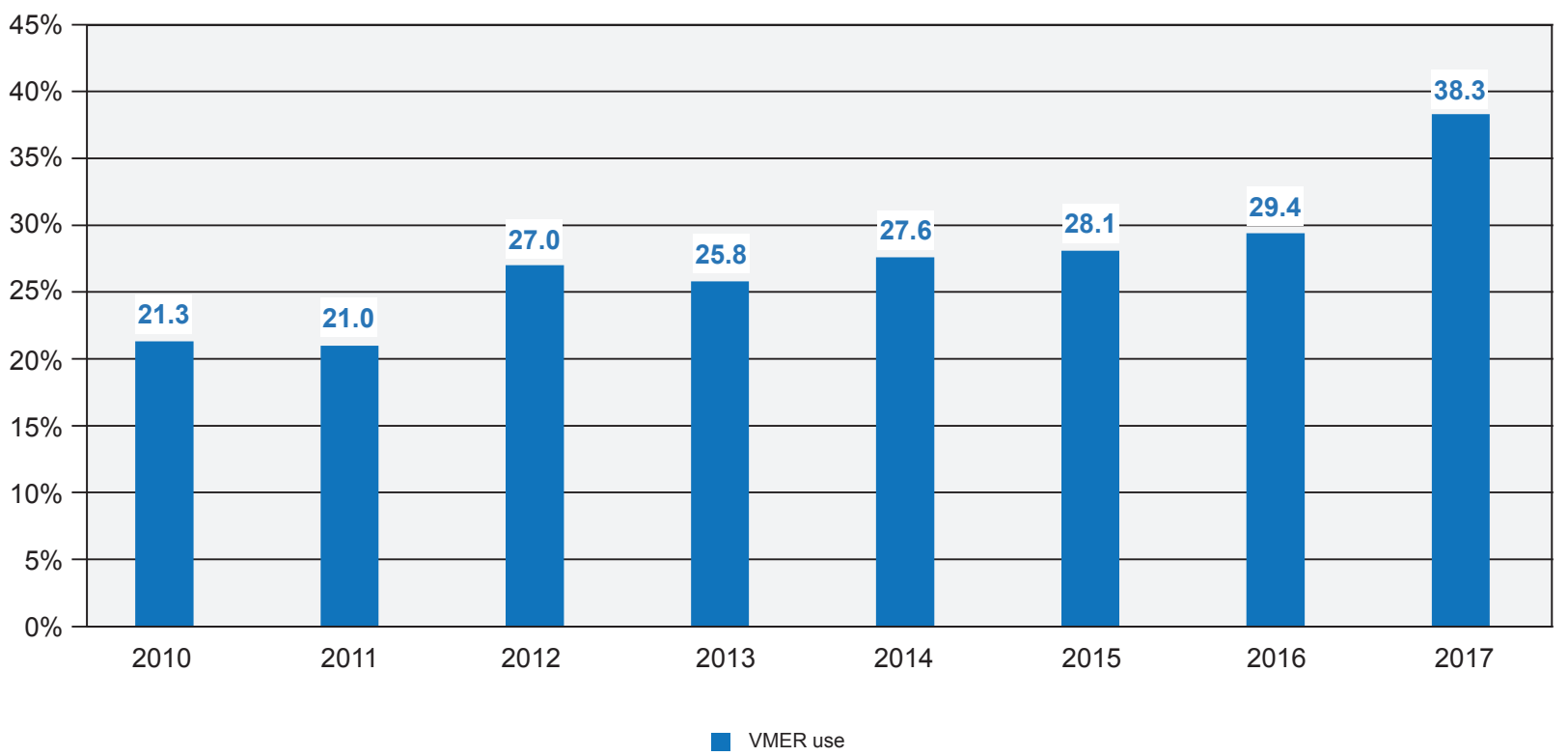

Figure 2 - Evolution of VMER use throughout the years 
Table 3 - Treatment delays to reperfusion in minutes

\begin{tabular}{|c|c|c|c|}
\hline & $\begin{array}{l}\text { STEMI transported by } \\
\text { emergency vehicles } \\
(n=1474)\end{array}$ & $\begin{array}{l}\text { STEMI transported } \\
\text { through other means } \\
(\mathrm{n}=4228)\end{array}$ & $p$ \\
\hline Time between symptoms and first medical contact & $116(60 ; 205)$ & $138(70 ; 310)$ & $<0.001$ \\
\hline Time between first medical contact and admission & $72(45 ; 105)$ & $80(43 ; 148)$ & $<0.001$ \\
\hline Time between symptoms and admission & $165(110 ; 271)$ & $183(99 ; 387)$ & 0.002 \\
\hline Time between symptoms and reperfusion & $208.5(150 ; 308)$ & $267(180 ; 435)$ & $<0.001$ \\
\hline Time between symptoms and needle & $165(120 ; 240)$ & $205(140 ; 297.5)$ & 0.012 \\
\hline Time between symptoms and balloon & $211(152 ; 314)$ & $270(181 ; 445)$ & $<0.001$ \\
\hline Time between first medical contact and reperfusion & $93(49 ; 139)$ & $120(75 ; 190)$ & $<0.001$ \\
\hline Time between first medical contact and needle & $71(40 ; 106)$ & $61.5(39 ; 105)$ & 0.994 \\
\hline Time between first medical contact and balloon & $94(50 ; 141)$ & $125(79 ; 195)$ & $<0.001$ \\
\hline Time between door and reperfusion & $30(15 ; 69)$ & $85(37 ; 160)$ & $<0.001$ \\
\hline Time between door and needle & $30(17 ; 64.5)$ & $42.5(20 ; 84.5)$ & 0.109 \\
\hline Time between door and balloon & $29(15 ; 69)$ & $88(40 ; 165)$ & $<0.001$ \\
\hline
\end{tabular}

All times are presented as median (P25; P75)

hand, patients from Group 2 are more likely to develop HF throughout the hospital stay $(p=0.018)$. When it comes to in-hospital mortality, there are no significant differences between the groups $(p=0.361)$.

Regarding in-hospital mortality, there is a specific subset of patients that are associated with a worse outcome. Women $(p<0.001)$ and patients with valve disease $(p=$ $0.037)$ and chronic kidney disease $(p=0.015)$ are associated with higher mortality. Cardiac arrest $(p=0.008)$, shock ( $p$ $<0.001)$ and atrial fibrillation $(p<0.001)$ represent high-risk clinical features that culminate in a worse outcome. Also, the presence of right bundle branch block (RBBB) is associated with higher mortality $(p=0.001)$, as described in the literature. ${ }^{17}$ Patients with left ventricular systolic dysfunction $(p<0.001)$ and multivessel disease $(p=0.031)$ are associated with higher in-hospital mortality.

\section{DISCUSSION}

Cardiovascular diseases are the most common cause of death in European countries. ${ }^{1-3,6,18}$ Even though hospitalization rates seem to have remained stable in the last few decades, STEMI rates are declining, probably due to improved coronary risk factor awareness. ${ }^{18}$ Improvements in treatment improved CVD prognosis, as shown by the steady reduction in mortality and morbidity. ${ }^{2-4,6,18}$ Hartley et $a^{R}$ described an estimated annual percentage change in IHD mortality in Portugal of $-1.74 \%$ and $-1.47 \%$ from 1980 to 2004 and of $-8.44 \%$ and $-8.20 \%$ from 2005 to 2009 , in male and female patients, respectively. Townsend et $a^{\beta}$ also reported that from 2003 to 2013 there was a $40.1 \%$ and $42.9 \%$ reduction in the age-standardized mortality rate by IHD in Portuguese men and women, respectively. The European Cardiovascular Disease Statistics 2017 report described a reduction in death rates from IHD from 220 and 125 deaths per 100000 in 1980 to 98 and 49 deaths per 100000 in 2014, in Portuguese men and women, respec- tively. ${ }^{6}$ IHD is also the leading cause of death in both men and women under 65 years of age, ${ }^{6}$ which is important for this population since STEMI tends to affect younger patients more predominantly. ${ }^{1}$ In Portugal, there is a less steady but effective decline in premature mortality by IHD, with death rates of 46 and 12 deaths per 100000 in 1980 compared to 28 and 4 deaths per 100000 in 2014, in men and women under 65 years of age, respectively. ${ }^{6}$ This overall reduction in cardiovascular mortality is certainly related with improvements in pharmacological therapy and to an increase in $\mathrm{PCl}$ accessibility. ${ }^{19}$ Pereira et a/ ${ }^{5}$ reported a significant increase in P-PCl from 2002 to 2013, thus promoting mortality and morbidity reduction in STEMI patients. The same group ${ }^{5}$ also demonstrated the change in the paradigm in STEMI treatment, notably P-PCl overtaking rescue angioplasty as the predominant procedure since 2006.

To truly impact prognosis, the most important part of the STEMI treatment is a timely reperfusion, ideally through $\mathrm{P}$ $\mathrm{PCl}^{1,20} \mathrm{P}-\mathrm{PCl}$ is superior to $\mathrm{FT}$ in terms of mortality reduction, reinfarction and stroke, if treatment delay is comparable..$^{1,20}$ Nevertheless, if $\mathrm{P}-\mathrm{PCl}$ is expected to be carried out with significant delay, FT is preferable since it can be initiated hastily. 8,9 Treatment delay depends on patient-delay and on system-delay. Patient-delay is difficult to minimize. ${ }^{1}$ The REACT trial ${ }^{21}$ employed a series of public education campaigns in a community to evaluate differences in patient-delay. Luepker et $a^{21}$ determined that the intervention, while significantly increasing EMS use, time between symptom onset and hospital arrival was not significantly different. In Portugal's case, the European initiative Stent for Life strategy has been implemented. ${ }^{22}$ A series of national campaigns to improve public awareness, as well as organizational measures involving INEM and hospital performance, were applied with plans to improve the network of $\mathrm{P}-\mathrm{PCl}$ centres and thus increasing the number of patients treated by $\mathrm{PCl}$ in cases of STEMI. ${ }^{22}$ The initiative enhanced 
Table 4 - Therapeutic strategies

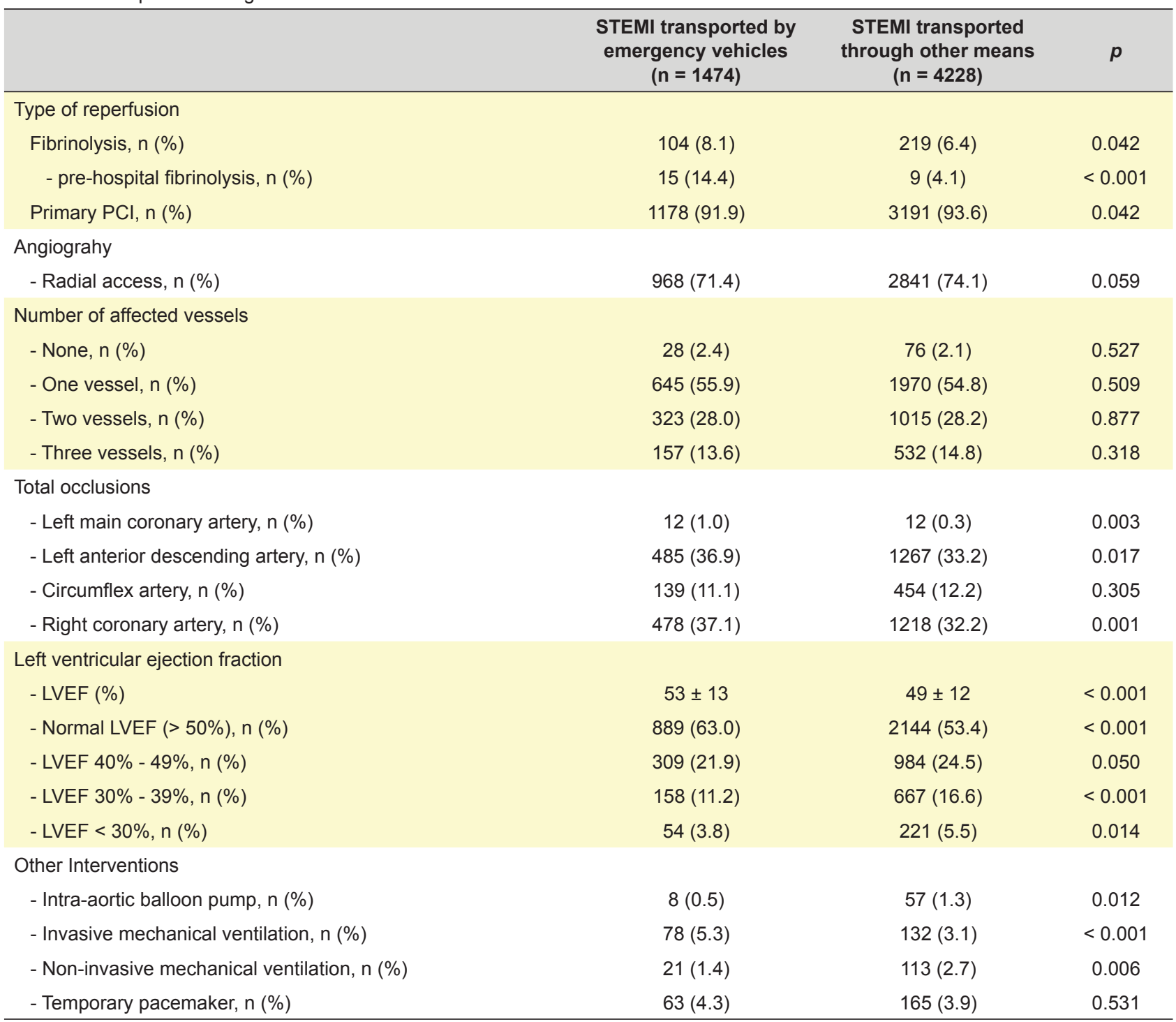

Table 5 - In-hospital mortality and complications

\begin{tabular}{|c|c|c|c|}
\hline & $\begin{array}{l}\text { STEMI transported by } \\
\text { emergency vehicles } \\
(n=1474)\end{array}$ & $\begin{array}{l}\text { STEMI transported } \\
\text { through other means } \\
(\mathrm{n}=4228)\end{array}$ & $p$ \\
\hline Length of hospital stay in days, median (P25; P75) & $3(2 ; 5)$ & $4(3 ; 5)$ & 0.006 \\
\hline \multicolumn{4}{|l|}{ Adverse events during hospital stay } \\
\hline Re-Infarction, n (\%) & $9(0.6)$ & $41(1.0)$ & 0.202 \\
\hline Heart failure, $\mathrm{n}(\%)$ & $255(17.3)$ & $850(20.1)$ & 0.018 \\
\hline Shock, n (\%) & $109(7.4)$ & $258(6.1)$ & 0.083 \\
\hline Worsening of Killip-Kimball class, n (\%) & $152(10.4)$ & $500(11.9)$ & 0.110 \\
\hline Atrial fibrillation, $\mathrm{n}(\%)$ & $97(6.6)$ & $289(6.8)$ & 0.731 \\
\hline Mechanical complication, n (\%) & $15(1.0)$ & $60(1.4)$ & 0.243 \\
\hline Atrioventricular block, $\mathrm{n}(\%)$ & $84(5.7)$ & $233(5.5)$ & 0.795 \\
\hline Sustained ventricular tachycardia, n (\%) & $59(4.0)$ & $109(2.6)$ & 0.005 \\
\hline Aborted cardiac arrest, $\mathrm{n}(\%)$ & $121(8.2)$ & $213(5.0)$ & $<0.001$ \\
\hline Stroke, n (\%) & $10(0.7)$ & $34(0.8)$ & 0.633 \\
\hline Major bleeding, n (\%) & $31(2.1)$ & $83(2.0)$ & 0.744 \\
\hline In-hospital mortality & $84(5.7)$ & $215(5.1)$ & 0.361 \\
\hline
\end{tabular}


EMS use and shortened revascularization times due to reduced patient-delay; system-delay remained unchanged however. ${ }^{22}$ Reducing system-delay is only possible through organizational measures,,$^{1,23}$ and according to Terkelsen et $a l^{10}$ it can have an impact on mortality. Fordyce et $a^{23}$ recently presented the results of the implementation of the STEMI Systems Accelerator program, which was applied in the United States. They described four key care processes: (1) prehospital catheterization laboratory activation; (2) single call transfers to $\mathrm{PCl}$ capable hospitals for patients presenting to a non-PCl-capable centre; (3) ED bypass for patients referred via EMS; (4) ED bypass for patients transferred from a non-PCl-capable centre. ${ }^{23}$ EMS played an important part in employing the implementation of the initiative. ${ }^{23}$ Fordyce et $a^{23}$ proved that, even though reperfusion times and system-delay was significantly reduced, mortality remained unchanged. In fact, EMS transportation is cru-

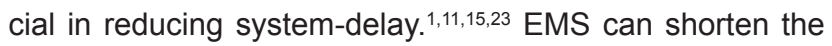
time to reperfusion by arriving faster to the patient location and providing earlier transport to $\mathrm{PCl}$-capable centres or administration of on-site fibrinolysis (O-FT). ${ }^{1,15,24}$ EMS can make available advanced cardiac life support personnel in a pre-hospital setting. ${ }^{15}$ EMS can dispatch STEMI alert to the nearest $\mathrm{PCl}$-capable centre or even activate catheterization lab in a pre-hospital setting, thus reducing door to balloon times. ${ }^{11,12,14}$ However, despite the benefits the EMS seems to carry, most published studies do not seem to report reduced mortality. ${ }^{15,23}$

Regarding our population, men, patients with higher cardiovascular risk (namely dyslipidaemia and smoking habits) and known coronary disease tend to have higher usage of EMS vehicles. There was no significant difference in age. These findings were in some respects similar to what Canto et al reported. ${ }^{15}$ Canto et al ${ }^{15}$ evaluated EMS use in cases of AMI. When compared to our population, the biggest differences were: (1) men had 19\% lower chance of using EMS; (2) the odds of EMS use were $21 \%$ higher with each increasing decade of life; (3) previous stroke or cardiac history tended to have higher EMS use. ${ }^{15}$ In our population, patients with extreme weights (low weight or obese patients) were more likely to be transported via VMER, which was not accounted for by Canto et a/ ${ }^{15}$ Another important aspect that affected EMS use was the characteristics of the chest pain. The presence of persistent chest pain was independently associated with EMS use. On the other, paroxysmal chest pain was less likely to use VMER.

Another important fact was the steady rise in VMER use in STEMI patients. The implementation of public awareness initiatives, like the aforementioned Stent for Life, has certainly made an impact in informing the general public. This steady increase of VMER use from $21.3 \%$ in 2010 to $38.3 \%$ in 2017 ( $p<0.001)$ has been proven to be associated with significant patient- and system-delay reduction. ${ }^{22}$ Notably, there is a significant lower rate of EMS transportation in Northern Portugal, a situation that merits the reinforcement of public awareness initiatives in this region to improve overall timings.
The greatest benefits that derive from EMS use are the reduction in reperfusion timings. Studies consistently show an impact of EMS transportation in reducing treatment delay. 1,10,12-15,23 This study showed that, in Portugal, this is no exception, VMER transportation ensured a 58-minute reduction of the median reperfusion time $(p<0.001)$. VMER reduced the time between symptoms and the first medical contact (FMC), thus enabling a faster STEMI diagnosis. VMER also shortened the time between symptoms and hospital admission, playing a part in ensuring a faster transportation to the hospital, while providing advanced life support if necessary. Another important aspect is the reduction of the time between hospital admission and beginning of the $\mathrm{PCl}$ procedure. EMS transportation is known to reduce Door to Balloon (D2B) times, ${ }^{12,15}$ as is the case with our population, and that reduction has been proven to reduce mortality in the study by Nallamothu, ${ }^{25}$ though that reduction was not evident in a study by Menees. ${ }^{26}$ EMS has an important role in ensuring a field triage as well, thus enabling direct transfer to a PCl-capable centre, which may have an impact on mortality. ${ }^{11,23}$ In our population, VMER was associated with a significant lower incidence of admission to a non-PCl-capable centre, demonstrating the importance of field triage and following protocols according to geographical areas of responsibility. However, there is still a high rate of transportation to a non-PCl-capable centre in the VMER group, which is not satisfactory. The authors suspect that this is probably due to two main reasons: (1) misdiagnosis of STEMI and thus transporting to the nearest hospital; (2) impossibility of administering on-site fibrinolysis, in a setting of an expectable delay of over 120 minutes for transportation to a PCl-capable centre, and thus transportation to the nearest hospital being able to initiate FT expeditiously. EMS can also expedite pre-hospital Cath lab activation, reducing D2B times, however the risk of false positive activation is a factor that must be accounted for. This possibility is more frequent in pre-hospital STEMI diagnosis. ${ }^{12,14}$ Again, in Portugal, VMER ensured a higher rate of ED bypass and of direct admission to the Cath lab, therefore playing an important role in the reduction of the system-delay.

Perhaps the most unexpected finding was that some timings related with $\mathrm{FT}$ were not significantly reduced, namely the time between FMC and FT and between hospital admission and FT. Strikingly enough, the time between FMC and beginning of FT was higher in the EMS group, albeit not significantly. These findings were different from what is described in other studies, which consistently describe shorter times to FT in patients transported by EMS. ${ }^{15,27}$ The authors suspect that this might have happened due to possible misdiagnosis of STEMI, inability to administer O-FT, poor coordination of the emergency systems, or simply because the time between FMC with VMER (which occurs in a pre-hospital setting) and FT is understandably higher when compared to in-hospital FMC and FT when O-FT is not available. Fortunately, the overall timing between symptoms and FT ended up being significantly reduced in Group 1 , which reflects the benefits of EMS in arriving faster to 
the patient's location, thus reducing the time between symptom and FMC. VMER enhanced the patients' chances of receiving O-FT (14.4\% vs $4.1 \%, p<0.001)$. Pre-hospital fibrinolysis has a definite impact on prognosis if administered early after symptom onset and if transportation to a $\mathrm{PCl}$-ready centre is expected to have a relevant delay, with the 120-minute mark being the most consistent interval reported. ${ }^{1,7,27-30}$ If possible, FT should be administered in a pre-hospital setting..$^{1,29-31}$ The presence of an EMS vehicle with medical staff can certainly play a part in increasing the rate of pre-hospital fibrinolysis. Studies reveal that O-FT administered by trained staff was associated with a higher adherence to protocols and a decrease in treatment delay and might be associated with lower mortality. ${ }^{24,27}$ This finding also raises another question regarding the small number of cases in which FT was administered outside the hospital setting in the absence of an EMS team. Since this is a retrospective and observational study, it is impossible to determine when, where and how these events occurred. It is the authors' opinion that possibly these cases happened in primary health care centres, where it is possible to administer fibrinolysis with medical supervision and with posterior referral ed ce «ospto $\mathrm{PCl}$-capable centres through transportation means outside the EMS network. These results reveal an issue that must be addressed in order to improve our care, namely the need to reduce the time between symptoms and FT. Organizational measures should be enforced to guarantee that every VMER is capable of administering $\mathrm{FT}$ and adequate training should be given to the VMER staff to ensure the administration of FT in the recommended 10-minute interval, if transportation to a $\mathrm{PCl}$ capable centre delay is expected.

Regarding the primary objective of the study, unfortunately EMS transport was not associated with mortality reduction nationwide. This finding is consistent with what is described in other studies. Canto et a/ ${ }^{15}$ described higher crude mortality in the EMS group, which was explained by the fact that the EMS population represented a much sicker cohort. In Portugal, the same applies. The population transported by VMER represents patients of higher risk. There is a higher prevalence of cardiac arrest upon admission and throughout hospitalization, consistent lower blood pressure, higher rate of total occlusion of the left main, left anterior and right coronary arteries, more frequent occurrence of ventricular tachycardia and higher usage of invasive mechanical ventilation (which is significantly related to the higher rate of cardiac arrest, $Q Q$ test $p$-value of $<0.001)$. After individual evaluation of each specific subset of patients regarding KK class and occurrence of cardiac arrest, there was also no significant difference in mortality. The main benefit detected in the VMER group was the significant decrease in development of HF. This fact is related to the finding of consistently higher LVEF and lower BNP levels in Group 1. This is also associated with the higher usage of Intra-aortic balloon pump and non-invasive mechanical ventilation in the treatment of HF in group 2 (both procedures were significantly related to HF occurrence, $Q Q$ test $p$-value of $<0.001)$.
This benefit in LVEF and HF is the result of shorter reperfusion times. Longer duration of coronary occlusion results in progressive extension of the infarction area and subsequent reduction of the amount of salvageable myocardium. ${ }^{28}$ The reduction in overall reperfusion timings attained by VMER resulted in a greater amount of salvaged myocardium and thus led to a higher LVEF and subsequently lower occurrence of HF. Another interesting aspect would be evaluating if VMER transportation had an impact in long-term prognosis. According to the literature, left ventricular systolic dysfunction is a strong predictor of in-hospital and long-term mortality. ${ }^{1,26,33}$ Since the shorter reperfusion times found in the VMER group resulted in higher LVEF, one could expect better long-term results in that group. However, due to restraints in the RNSCA, it is not possible to evaluate longterm mortality in our population.

\section{Limitations}

This study comprises all the limitations that are inherent to national registries. First, not all centres participate in the RNSCA. Each participation is voluntary, so it relies on the accurate description of every ACS case in each centre, which might not include all patients. Since this is a retrospective study, it is impossible to determine the criteria used in selecting which patients were transported by VMER. Due to registry restraints, the authors do not have access to each individual centre's data, meaning it is not possible to evaluate the reasons for each individual treatment strategy. This is an observational study; thus, it has all the limitations associated with this method. There was no randomization performed throughout the study and it is impossible to infer causality in some of the parameters that are being analysed. Thus, the results obtained can only be considered indicative.

\section{CONCLUSION}

This article reflects the real-world data happening in Portugal. The RNSCA is an invaluable tool in evaluating the current management of ACS in a nationwide setting and can provide useful tools to improve our standard of care. EMS transportation plays a crucial role in the treatment of STEMI. Nationwide, it is evident that EMS is associated with a series of benefits: (1) it ensures transportation for patients with higher cardiovascular risk and with more critical clinical presentation; (2) it effectively shortens reperfusion times and enhances the possibility of O-FT when $\mathrm{PCl}$ is expected to be delayed; (3) it is associated with a higher amount of salvaged myocardium, as reflected by the higher LVEF, and thus reduces the incidence of HF and possibly enhancing long-term prognosis. Though these benefits were evident, VMER transportation does not impact in-hospital mortality. Probably, this is a result of confounding factors of disease severity and comorbidity in patients that are transported by VMER. Therefore, while this paper was unable to report mortality benefit, a longer follow-up could demonstrate the importance of VMER transportation in long-term prognosis. 


\section{OBSERVATIONS}

A previous version of this work with fewer patients was presented in the Portuguese Congress of Cardiology 2016.

\section{PROTECTION OF HUMANS AND ANIMALS}

The authors declare that the procedures were followed according to the regulations established by the Clinical Research and Ethics Committee and to the Helsinki Declaration of the World Medical Association.

\section{DATA CONFIDENTIALITY}

The authors declare having followed the protocols in use at their working center regarding patients' data publication.

\section{CONFLICTS OF INTEREST}

The authors declare that there are no conflicts of interest nor any form of support.

\section{FUNDING SOURCES}

This research received no specific grant from any funding agency in the public, commercial, or not-for-profit sectors.

15. Canto J, Zalenski R, Ornato J, Rogers W, Kiefe C, Magid D, et al. Use of emergency medical services in acute myocardial infarction and subsequent quality of care: observations from the National Registry of Myocardial Infarction 2. Circulation. 2002;106:3018-23.

16. Santos J, Aguiar C, Gavina C, Azevedo P, Morais J; Registo Nacional de Síndromes Coronárias Agudas da Sociedade. Portuguese Registry of Acute Coronary Syndromes: seven years of activity. Rev Port Cardiol. 2009;28:1465-500

17. Widimsky P, Rohac F, Stasek J, Kala P, Rokyta R, Kuzmanov B, et al. Primary angioplasty in acute myocardial infarction with right bundle branch block: should new onset right bundle branch block be added to future guidelines as an indication for reperfusion therapy? Eur Heart J. 2012;33:86-95.

18. McManus D, Gore J, Yarzebski J, Spencer F, Lessard D, Goldberg R. Recent trends in the incidence, treatment, and outcomes of patients with STEMI and NSTEMI. Am J Med. 2011;124:40-7.

19. Pereira H, Teles R, Costa M, da Silva P, Ferreira R, da Gama Ribeiro $\mathrm{V}$, et al. Trends in percutaneous coronary intervention from 2004 to 2013 according to the Portuguese National Registry of Interventional Cardiology. Rev Port Cardiol. 2015;34:673-81.

20. Keeley EC, Boura JA, Grines CL. Primary angioplasty versus intravenous thrombolytic therapy for acute myocardial infarction: a quantitative review of 23 randomised trials. Lancet. 2003;361:13-20.

21. Luepker R, Raczynski J, Osganian S, Goldberg R, Finnegan J Jr, Hedges $\mathrm{J}$, et al. Effect of a community intervention on patient delay and emergency medical service use in acute coronary heart disease: The Rapid Early Action for Coronary Treatment (REACT) Trial. JAMA. 2000;284:60-7.

22. Pereira H, Pinto FJ, Calé R, Pereira E, Marques J, Almeida M, et al Stent for Life in Portugal: this initiative is here to stay. Rev Port Cardiol. 2014;33:363-70.

23. Fordyce $\mathrm{C}, \mathrm{Al}-$ Khalidi $\mathrm{H}$, Jollis J, Roettig M, Gu J, Bagai A, et al. Association of rapid care process implementation on reperfusion times across multiple ST-segment elevation myocardial infarction networks. Circ Cardiovasc Interv. 2017;10:e004061.

24. Welsh R, Chang W, Goldstein P, Adgey J, Granger C, Verheugt F, et al. Time to treatment and the impact of a physician on prehospital management of acute ST elevation myocardial infarction: insights from the ASSENT-3 PLUS trial. Heart. 2005;91:1400-6.

25. Nallamothu B, Normand S, Wang Y, Hofer T, Brush J Jr, Messenger J, et al. Relation between door-to-balloon times and mortality after primary percutaneous coronary intervention over time: a retrospective study. Lancet. 2015;385:1114-22.

26. Menees D, Peterson E, Wang Y, Curtis J, Messenger J, Rumsfeld J, et al. Door-to-Balloon time and mortality among patients undergoing primary PCl. N Engl J Med. 2013;369:901-9.

27. Bjorklund E, Stenestrand U, Lindback J, Svensson L, Wallentin L, Lindah B. Prehospital thrombolysis delivered by paramedics is associated with reduced time delay and mortality in ambulance-transported reallife patients with ST-elevation myocardial infarction. Eur Heart J. 2006;27:1146-52.

28. Boersma E, Maas A, Deckers J, Simoons M. Early thrombolytic treatment in acute myocardial infarction: reappraisal of the golden hour. Lancet 1996;348:771-5.

29. Sinnaeve P, Armstrong P, Gershlick A, Goldstein P, Wilcox R, Lambert Y, et al. ST-segment-elevation myocardial infarction patients randomized 
to a pharmaco-invasive strategy or primary percutaneous coronary intervention: Strategic Reperfusion Early After Myocardial Infarction (STREAM) 1-year mortality follow-up. Circulation. 2014;130:1139-45.

30. Morrison L, Verbeck P, McDonald A, Sawadsky B, Cook D. Mortality and prehospital thrombolysis for acute myocardial infarction: a metaanalysis. JAMA. 2000;283:2686-92.

31. Bonnefoy E, Steg P, Boutitie F, Dubien P, Lapostolle F, Roncalli J, et al. Comparison of primary angioplasty and pre-hospital fibrinolysis in acute myocardial infarction (CAPTIM) trial: a 5-year follow-up. Eur Heart J.
2009;30:1598-606.

32. van der Vleuten P, Rasoul S, Huurnink W, van der Horst I, Slart R, Reiffers $S$, et al. The importance of left ventricular function for longterm outcome after primary percutaneous coronary intervention. BMC Cardiovasc Disord. 2008;8:4.

33. Ng V, Lansky A, Meller S, Witzenbichler B, Guagliumi G, Peruga J, et al. The prognostic importance of left ventricular function in patients with ST-segment elevation myocardial infarction: the HORIZONS-AMI trial. Eur Heart J Acute Cardiovasc Care. 2014;3:67-77. 